\title{
Zum neuen türkischen Parteiengesetz
}

\author{
Von Zehra Önder
}

Das Militärregime in der Türkei hat im April 1983 das neue Parteiengesetz (Siyasi Partiler Kanunu) erlassen. Diesem neuen Parteiengesetz ging eine Reihe von Entwicklungen voraus, die den Rahmen des Gesetzes festlegten.

Im September $1980 \mathrm{kam}$ in der Türkei zum dritten mal das Militär an die Macht. Die Begründung dabei war simpel: Die Ruhe und Ordnung sollte wiederhergestellt und dem Terror im Lande ein Ende gemacht werden. Im Ausland wurden die Entwicklungen in der Türkei mit den Links-Rechts-Kämpfen mit Spannung verfolgt. Die politischen sozio-kulturellen und ökonomischen Ursachen dieses Durchbruchs blieben jedoch weitgehend unberücksichtigt.

Zwei Aspekte wurden von dem Militärregime besonders hervorgehoben: Die Rückkehr zum kemalistischen Nationalismus und Maßnahmen gegen die Linke, gegen die kommunistische Gefahr im Lande. Diese beiden Aspekte sind im neuen Parteiengesetz fast durchgehend zu finden. Deshalb hatte der Führer des militärischen Coup, General Kenan Evren, mit einem Gesetz von Anfang Oktober 1981 (Nr. 2533) die bis zum Militärputsch die politische Szene in der Türkei bestimmenden Parteien aufgelöst.

Die Türkei sollte mit Hilfe des Militärs eine neue Parteien-Demokratie erhalten, die den Vorstellungen der Armee entspricht. Schließlich hatte Kemal, Gründer der NationalTürkei, das Militär zum Hüter der türkischen Nation erklärt. Der Eingriff des Militärs ist kemalistisch legitimiert. Das politische, wirtschaftliche und sozio-kulturelle Schicksal des Landes hängt also von der türkischen Armee, von ihren Sanktionen oder ihrer Toleranz ab.

Das neue Parteiengesetz soll einen Neubeginn im politischen Leben in der Türkei markieren und das kemalistische Fundament, von dem sich die Türkei, so glaubt die Armee, in den 70er Jahren abermals distanziert hatte, wieder herstellen. Das Gesetz befaßt sich im ersten Teil mit den allgemeinen Bestimmungen. Der zweite Teil ist von besonderer Relevanz, da er sich mit der Organisation, der Mitgliedschaft und anderen Bestimmungen der Parteien befaßt. In diesem Teil wird deutlich, wie sehr versucht wird, Autonomiebestrebungen, insbesondere der Kurden und Araber mit allen Mitteln zu verhindern.

Der türkische Nationalismus hatte sich schon gleich nach der Gründung der republikanischen Türkei auf allen Ebenen bemerkbar gemacht. Kemal bestritt gleich nach der Ubernahme der Macht jegliche Existenz von Nicht-Türken, machte jedoch durch seine Türkisierungspolitik das Leben den Nicht-Türken besonders schwer. Nicht die geringste Rücksicht wurden auf Kultur und Sprache genommen. In allen anderen Bereichen jedoch, Wirtschaft, Politik oder im Erziehungsbereich ließ man sie völlig im Stich. 
In diesem Rahmen ist auch die militärische Intervention zu sehen. Die westlichen Medien deuteten die militärische Machtergreifung überwiegend positiv. Sie sollte in das von bürgerkriegsähnlichen Kämpfen erschütterte Land Stabilität bringen. Die tiefergehenden Ursachen blieben abermals unberücksichtigt.

So wird im ersten Teil des neuen Parteiengesetzes zu verstehen gegeben, daß die Gründung von Parteien, die die Einheit der Türkei in Frage stellen, die Herrschaft einer Klasse oder sprachliche, rassistische und religiöse Ziele anstreben, untersagt sind. Hier sind die Ängste der Nation deutlich herauszulesen.

Im zweiten Teil (Abs. 8) des Gesetzes wird darauf hingewiesen, daß mindestens 30 türkische Staatsbürger erfolgreich seien, um eine Partei zu gründen. Bei ihrem Antrag auf eine Parteigründung müssen die Parteien ferner Informationen über die einzelnen Mitglieder und das Parteiprogramm vorlegen.

Die Voraussetzungen für die Mitgliedschaft in einer Partei werden im zweiten Abschnitt (Teil 2) ausführlich dargelegt. Hochschullehrer, Staatsbeamte, Schüler und Studenten, Angehörige der Armee dürfen demnach keiner politischen Partei angehören (Abs. 11). Es handelt sich um die Eliten, die bei den alten Parteien dominierten. Das soll sich nach dem neuen Parteiengesetz ändern. Stärkere politische Aktivität wird von Händlern, Grundbesitzern, Unternehmern, Freiberuflern wie Ärzte, Rechtsanwälte, Kleingewerblern sowie von Bauern und Arbeitern erwartet. Was damit bezweckt werden sollte, ist unklar. Fest steht jedoch, daß Hochschullehrer und Studenten bei den Unruhen eine wichtige Rolle gespielt haben. Staatsbeamte und Offiziere könnten ihre Ämter politisch mißbrauchen. Es mag sein, daß diese Uberlegung im Hintergrund gestanden hat. Möglich ist aber auch, dal das ganze experimentellen Charakter hat, um festzustellen, ob Unruhen dadurch zu unterdrücken sind.

Von der Parteimitgliedschaft sind ferner solche Personen ausgeschlossen, die eine Straftat begangen haben und zu drei Jahren und mehr Gefängnis verurteilt wurden (Abs. 11/ 2), insbesondere solche, die wegen Aufwiegelung (tahkir etmek sucundan mahkum olanlar) bestraft worden sind (vgl. türkisches Strafgesetz Nr. 312, Abs. 11/4).

Die religiöse Renaissance hat lange Zeit das Militär mit seinem Drang zum kemalistischen Fundamentalismus gestört. Schließlich war Kemal ein Produkt europäisch-nationalistischer Strömungen, die bereits im 19. Jahrhundert Eingang in das osmanische Reich gefunden hatten. Der Säkularismus wurde so ein Kardinal-Prinzip des kemalistischen Nationalismus.

Der Kemalismus hat von Anfang an jegliche religiöse Tendenzen bekämpft. Da das kemalistische Regime faktisch ein Militärregime war, sieht sich die Armee seither auch als Hüter des kemalistischen Säkularismus.

Wer sich an das neue Parteiengesetz, an die neuen Bestimmungen also nicht hält, muß mit Disziplinarmalßnahmen rechnen (Abs. 53), die im zweiten Teil (Abschn. 8) ausführlich dargelegt werden.

Im dritten Teil, der im Gegensatz zu den auffälligen Úberschriften etc. des ersten und zweiten Teils den Eindruck erweckt, als wollte man ihn verstecken, enthält Bestimmungen über die Einnahmequellen der Parteien (Abs. 61). Hierunter fallen Mitglieds- und 
Abgeordnetenbeiträge ebenso wie Erlöse aus dem Verkauf von Partei-Plaketten, von Partei-Publikationen, sowie Einnahmen aus den Veranstaltungen der Parteien, wie Bälle, Konzerte, Partys etc. Hinzu kommen Partei-Einnahmen aus parteieigenem Vermögen und die Schenkungen der Stiftungen. Verschiedene Punkte, wie z. B. die Stiftungsbeiträge, bleiben ziemlich unklar und lassen diverse Interpretationen zu. Die Praxis wird zeigen, ob diese Finanzierungsbestimmungen einen Realitätsbezug haben.

Im vierten Abschnitt des dritten Teils sind diverse Verbote (cesitli Yasaklar) aufgezählt. Hier ist folgendes besonders bemerkenswert. Diskriminierende Organisationen und Parteien wie Frauen-Vereine, Jugend-Vereine sind nicht zugelassen (Abs. 91). Ferner heißt es im selben Abschnitt, daß die Politiker mit Organisationen, Gewerkschaften, Kooperativen und sonstigen Berufsorganisationen etc. nicht kooperieren dürfen. Hinzu kommt, daß ehemalige Parteien und ihre Nachfolgegründungen nicht zugelassen werden. Eine Partei, die weitgehend von Mitgliedern ehemaliger Parteien gegründet ist, ist ebenfalls zu verbieten.

Es gab wohl Versuche bei allen Parteien, die neuen Verbote zu umgehen. Die Medien berichteten u. a. über einen Freund des ehemaligen Ministerpräsidenten Demirel, dem ein derartiger Versuch vorgeworfen wurde. Evren hat dann Anfang Juni auch damit gedroht, die Wahlen, die für den 6. Nov. 1983 vorgesehen worden waren, zu verschieben, wenn es zu solchen Parteigründungen käme. Er wies dabei auf Haß- und Neidgefühle hin, die derartige Parteigründungen hervorrufen würden, und warf den alten Parteien vor, daß sie mit allen Mitteln versuchten, ihre Existenz und ihre "Philosophie" zu erhalten. Evren verbannte die Gründungsmitglieder der "Großtürkischen Partei" Hüsamettin Cindoruk, ebenso wie Mehmet Golan sowie ihnen nahestehende ehemalige Ministerpräsident, Demirel, in die Provinz Canakkale (SZ vom 1./2. Juni 1983).

Letztendlich geht es dem Militärregime darum, die Dominanz in der politischen Entwicklung des Landes, die nur kemalistisch legitimiert ist, weiterhin zu behaupten und das politische Leben unter Einfluß und Kontrolle zu behalten. Die Herrschaftsklasse der kemalitischen Türkei ist eine überwiegend militärische. Ansonsten gerät das kemalistische Gleichgewicht leicht ins schwanken.

Von diesem "Permanenz-Zustand" seit der Gründung der kemalistischen Republik ist das Volk, das seit dem 19. Jahrhundert zwischen Ideologien immer wieder hin und her gerissen wird, besonders stark getroffen. Es hat buchstäblich die Orientierung verloren. Werte und Normen sind durch äußere Einflüsse so sehr ins Wanken geraten, daß der Identitätsbruch einen Dauer-Krisen-Zustand erzeugt.

Wie das Militär unter diesen Bedingungen mit seinen veralteten Methoden Herr der Lage bleiben könnte, außer mit Gewaltanwendung, ist unklar.

Mit den ehemaligen Parteien geht das Militär besonders radikal um. Das neue Parteiengesetz verbietet alle Symbole, Namen etc., die irgendetwas mit ehemaligen Parteien zu tun haben (Abs. 96), sowie laut Gesetz Nr. 2533 vom 16. 10. 81, verboten wurden. Ferner werden Parteien, die kommunistische, anarchistische, faschistische, theoretische, nationale, sozialistische, religiöse, sprachliche, rassische, konfessionelle und regionale $\mathrm{Na}$ men tragen, nicht zugelassen (Abs. 96). 
Zu den genannten Verboten im Abschnitt 4 des zweiten Teils gehört auch, daß niemandem erlaubt ist, sich gegen den Militärputsch zu äußern (Abs. 97). Das Militärregime genießt also volle Immunität, auf Kosten der freien Meinungsäußerung und der persönlichen Freiheit.

Dieser Abschnitt ist besonders gefährlich, da alles für das Regime Unliebsame, langfristig gesehen, "beseitigt" werden kann. Eine langfristige Absicherung ist auch durch den vierten Abschnitt (zweiter Teil) gewährleistet. Danach können politische Parteien (nach ihrer Gründung) auf Antrag der Staatsanwaltschaft verboten werden (Abs. 98).

Hier werden die Ängste des Armeeregimes deutlich, die Lage in der Türkei mittel- und langfristig in den Griff zu bekommen.

Das Regime scheint entschlossen, per Gesetz alles zu unterbinden, was dem Militär im Laufe der Zeit mißfallen könnte. Diese Tendenz tritt auch durch die am Schluß des Gesetzestextes aufgeführten vorläufigen Bestimmungen hervor: Führende Parteifunktionäre dürfen sich 10 Jahre lang (mit Beginn der Volksabstimmung über die Verfassung, d. h. ab 1983) politisch nicht betätigen. Bei ehemaligen Abgeordneten und Senatoren ist diese Frist auf fünf Jahre beschränkt.

Gesetze machen nur dort Sinn, wo sie einen Realitätsbezug aufweisen, d. h. flexibel sind und Anpassung an reale Verhältnisse zulassen. Solche Ansätze sind jedoch bei dem Armeeregime bisher nicht zu verzeichnen. Der kranke Mann am Bosporus wird wohl auch weiterhin keine Ruhe finden, solange in- und ausländische Entscheidungsträger und Entscheidungshelfer sich den Realitäten dieses Landes verschließen. 